\title{
Enteroglucagon and experimental intestinal carcinogenesis in the rat
}

\author{
A P SAVAGE, J L MATTHEWS, M A GHATEI, T COOKE, AND S R BLOOM \\ From the Department of Medicine, Royal Postgraduate Medical School and Department of Surgery, Charing \\ Cross Hospital, London
}

SUMmARY To assess the association between the putative intestinal trophic hormone enteroglucagon and the development of intestinal tumours, four groups of 20 rats underwent either jejunal transection or $20 \%, 50 \%$, or $80 \%$ proximal small bowel resection. Tumours were induced with azoxymethane $10 \mathrm{mg} / \mathrm{kg}$ weekly for 12 weeks. At 26 weeks there was a promotion of colonic neoplasia from a median of 0.5 (range $0-3$ ) per rat in the transection group to $1.0(0-3)$ in the $50 \%$ resected group $(\mathrm{p}<0.01)$ but no significant promotion in the $80 \%$ resection group. In the small bowel, increasing resection resulted in a progressive promotion of tumours from a median of 1.0 (range $0-3$ ) per rat in the transection group to $2 \cdot 0(0-5)$ in the $50 \%$ resection group $(\mathrm{p}<0 \cdot 001)$ and $3 \cdot 0(0-11)$ in the $80 \%$ group $(\mathrm{p}<0.01)$. Plasma enteroglucagon was measured at 2 , 16 , and 26 weeks and was raised seven-fold in the $80 \%$ resected group $(\mathrm{p}<0 \cdot 001)$. There was a significant correlation between enteroglucagon concentrations and number of duodenal tumours but not colonic tumours. Crypt cell production rate in the duodenum increased from $11.5 \pm 1.9$ to $29 \cdot 2 \pm 1.4$ cells/crypt/h in the $80 \%$ resected group $(p<0 \cdot 001)$ and showed a close correlation with both enteroglucagon levels and tumour promotion in the small bowel. There were no changes in crypt cell production rate in the colon with resection. This study shows a close association between enteroglucagon concentrations, promotion of tumours and crypt cell production rate in the duodenum but not in the colon.

Small bowel resection promotes the development of colonic tumours in carcinogen treated animals ${ }^{1-4}$ and causes a moderate hyperplastic response in the colon. ${ }^{56}$ As hyperplasia is a feature of some premalignant lesions of the colon, promotion of tumours by intestinal resection has been attributed to this response. Hyperplasia, at least in the small intestine, is in part under hormonal control ${ }^{7-9}$ and enteroglucagon is the favoured candidate hormone mediating this response. ${ }^{10-1.3}$ Changes in trophic hormones may play a role in the promotion of colonic cancer. The aim of this study is to assess any association between enteroglucagon, intestinal cell proliferation, and the promotion of tumours induced by small bowel resection in an experimental rat model.

Address for correspondence: Professor S R Bloom, Department of Medicine, 2nd Floor Francis Fraser Lab., Royal Postgraduate Medical School, Hammersmith Hospital, Du Cane Road, London W12 0HS.

Received for publication 2 May 1986

\section{Methods}

ANIMALS

Eighty male Wistar rats weighing between 200 and $240 \mathrm{~g}$ were housed in groups of four in animal quarters with a 12 hour day/night cycle and were fed a standard pelleted rat food (Labsure, Poole, Dorset) with water ad libitum. Animals were randomly allocated to four groups. Group 1 underwent jejunal transection and reanastomosis alone and group 2 to 4 underwent $20 \%, 50 \%$, and $80 \%$ proximal small bowel resection as measured from ligament of Treitz to ileocaecal junction. All operations were done under inhalational anaesthesia with $50 \% \quad \mathrm{O}_{2} / 50 \% \quad \mathrm{~N}_{2} \mathrm{O}$ plus $3 \%$ halothane. Black silk interrupted sutures (5/0) were used for all anastomoses. One week after recovery from surgery all animals received the first of 12 weekly subcutaneous injections of azoxymethane $10 \mathrm{mg} / \mathrm{kg}$ (Ash Stevens, Detroit, USA). Rats were weighed weekly and weight gain expressed by subtracting the starting 
weight of each animal from all subsequent weights to accentuate any differences between the groups.

Animals were examined daily and were killed when moribund according to previously defined criteria ${ }^{14}$ or at the end of the study at 26 weeks. A full post mortem examination was carried out. The stomach, small bowel, caecum, and colon were dissected free, opened longitudinally, washed in saline and blotted dry. Site, size, and luminal appearance of all tumours were recorded and tumours with their adjacent normal bowel were fixed in $10 \%$ formalin in phosphate buffered saline before preparation for histological examination. Samples of duodenum, terminal ileum, caecum, and descending colon were taken for estimation of crypt cell production rate.

CRYPT CELL PRODUCTION RATE (CCPR)

A stathmokinetic technique was used to assess the rate of cell proliferation in the crypts of Lieberkuhn. ${ }^{15}{ }^{16}$ At 0800 on the morning of being killed each animal received an intraperitoneal injection of vincristine $1 \mathrm{mg} / \mathrm{kg}$ (Oncovin, Eli Lilly, Basingstoke). Rats were killed at intervals from 30 to 180 mins after injection. Samples of bowel were fixed in Carnoy's fixative for four hours and stored in $70 \%$ ethanol. Tissues were bulk stained by the Feulgen reaction and individual crypts microdissected. The number of metaphase arrested cells in 10 intact crypts for each site in each animal was counted and CCPR was derived as the slope of the line produced by least squares linear regression analysis of the mean number of metaphase arrested cells plotted against time.

HORMONE ASSAYS

Samples of blood were taken by tail vein puncture under light ether anaesthesia at two and 16 weeks and by cardiac puncture at 26 weeks. Samples were placed in heparinised tubes to which had been added $0.02 \mathrm{ml}$ (400 KIU) aprotinin (Trasylol) per ml blood. Plasma was separated immediately by centrifugation and samples frozen on dry ice and stored at $-20^{\circ} \mathrm{C}$ pending assay.

Enteroglucagon was measured by a standard radioimmunoassay technique described in full elsewhere. ${ }^{17}$ Two assays were carried out, one with an antibody (R50) which fully crossreacts with glicentin and one with an antibody (RCS5) directed to pancreatic glucagon which shows no crossreaction with glicentin. Enteroglucagon is derived by subtracting the small proportion of pancreatic glucagon from total glucagon immunoreactivity. This combined assay procedure will detect changes of 12 $\mathrm{pmol} / 1$ between adjacent plasma samples with $95 \%$ confidence.

\section{HISTOLOGY}

Formalin fixed tissues were embedded in paraffin blocks and multiple $5 \mu \mathrm{m}$ longitudinal sections were cut through bowel and tumours. Sections were stained with haematoxylin and eosin, and tumours were classified as benign or malignant according to whether there was invasion through the muscularis mucosa. ${ }^{18}$

\section{STATISTICAL ANALYSIS}

The Mann-Whitney $U$ test was used to assess differences in tumour number between the four groups except for ear canal tumour data which were analysed by Fisher's exact test. Enteroglucagon results are expressed as mean \pm standard error of the mean (SEM) and significance levels calculated by Student's unpaired $t$ test. The Spearman rank correlation coefficient was used to assess correlation between enteroglucagon levels, CCPR, and tumour numbers.

\section{Results}

MORTALITY AND WEIGHT GAIN

There was no significant difference in operative mortality between the four groups and overall mortality was $10 \%$. Early deaths, related to the development of intestinal tumours, were significantly more common in the $80 \%$ resected group $(p<0 \cdot 001$, Fisher's exact test) (Table 1). In groups 1 and 2 there were no early deaths, in group 3 there was one early death caused by intraperitoneal haemorrhage from a duodenal tumour. In group 4, two died from intraperitoneal haemorrhage from duodenal tumours and the remaining eight fulfilled the criteria for early death and were humanely killed. In these animals, the cause was related to large obstructing upper small intestinal or colonic tumours. There were no differences in the rate of weight gain between four and twenty weeks (Fig. 1). Only the $80 \%$ resected group lost weight as a result of surgery and this was regained by two weeks. After 20 weeks the $80 \%$ resected group lost weight.

Table 1 Operative mortality and disease related deaths.

\begin{tabular}{lcccc}
\hline & Control & \multicolumn{3}{c}{ Resection } \\
& Transection & $20 \%$ & $50 \%$ & $80 \%$ \\
\hline Operative mortality & 2 & 3 & 2 & 3 \\
Disease related deaths & 0 & 0 & 1 & $10^{*}$ \\
Number remaining & 18 & 17 & 17 & 7 \\
\hline
\end{tabular}

${ }^{*} \mathrm{p}<0 \cdot 001$, Fisher's exact test. 


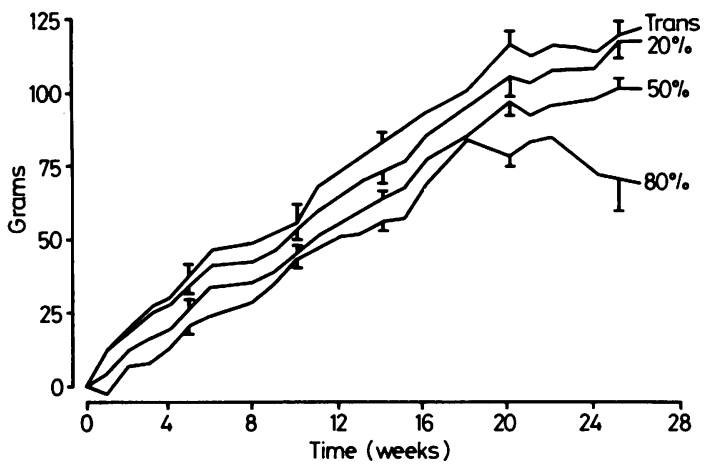

Fig. 1 Adjusted weight gain (mean $+S E M)$.

\section{TUMOURS}

Distribution

Colonic tumours developed mainly in the descending and transverse colon; small bowel resection did not change this pattern of distribution (Fig. 2). In the small bowel, tumours occurred predominantly in the first $3 \mathrm{~cm}$ of duodenum and around the anastomosis. Small bowel resection did not significantly affect the proportion of tumours occurring at the anastomosis. Histological examination confirmed neoplasia in all tumours and was able to provide an accurate classification into benign adenomas and malignant adenocarcinomas in $92 \%$ of specimens. Small bowel resection did not significantly affect the benign:malignant ratio of the tumours (Table 2).

\section{Number}

Small bowel resection resulted in a significant increase in the number of colonic tumours between the transection group and the $50 \%$ resected group $(\mathrm{p}<0.01)$, but not the $80 \%$ resected group (Table 3$)$.

In the small bowel, resection resulted in a steady promotion of tumours which was significant between the transected group and the $50 \%$ resected group $(\mathrm{p}<0.001)$ and the $80 \%$ resected group $(p<0.001)($ Table 3).
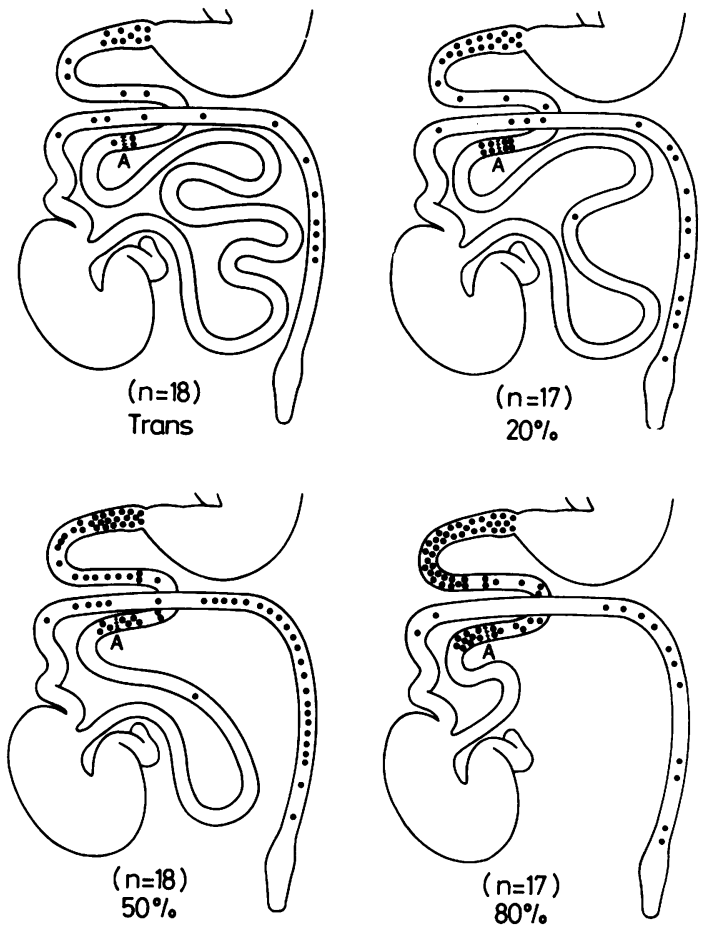

Fig. 2 Tumour distribution. A=Anastamosis.

The animals also developed external ear canal tumours. Histologically, these were papillomas or papillary carcinomas. Only one of 18 rats in the transected group developed these tumours compared with eight out of 17 rats in the $50 \%$ group and four of seven surviving animals in the $80 \%$ group $(\mathrm{p}<0.025)($ Table 3$)$.

\section{ENTEROGLUCAGON}

There was a seven-fold increase in enteroglucagon concentrations from $53 \pm 4.4 \mathrm{pmol} / / \mathrm{l}$ in the transection group to $358 \pm 60 \mathrm{pmol} / \mathrm{l}$ in the $80 \%$ resection group $(\mathrm{p}<0 \cdot 001)$. This response was present at two weeks and was maintained to the end of the study at

Table 2 Number and percentage in brackets of benign and malignant tumours by site in each group

\begin{tabular}{|c|c|c|c|c|c|c|}
\hline & \multicolumn{3}{|l|}{ Colon } & \multicolumn{3}{|c|}{ Small bowel } \\
\hline & $\begin{array}{l}\text { Adeno- } \\
\text { carcinoma }\end{array}$ & Adenoma & $N / C$ & $\begin{array}{l}\text { Adeno- } \\
\text { carcinoma }\end{array}$ & Adenoma & $N / C$ \\
\hline Trans & $8(67)$ & $4(33)$ & $0(0)$ & $15(88)$ & $2(12)$ & $0(0)$ \\
\hline $20 \%$ & $9(60)$ & $5(33)$ & $1(7)$ & $19(68)$ & $6(21)$ & 3 (11) \\
\hline $50 \%$ & $18(62)$ & $11(38)$ & $0(0)$ & $30(68)$ & $12(27)$ & $2(5)$ \\
\hline $80 \%$ & $5(38 \cdot 5)$ & $5(38 \cdot 5)$ & $3(23)$ & $43(70)$ & 9 (15) & 9 (15) \\
\hline
\end{tabular}

$\mathrm{N} / \mathrm{C}=$ Tumours not accurately classifiable into benign or malignant. 
Table 3 Tumours in each site

\begin{tabular}{|c|c|c|c|c|c|c|c|c|c|}
\hline & \multirow[b]{2}{*}{ (n) } & \multicolumn{3}{|l|}{ Colon } & \multicolumn{3}{|c|}{ Duodenum } & \multicolumn{2}{|c|}{ Ear canal } \\
\hline & & Median & Mean & Range & Median & Mean & Range & Tumour & No tumour \\
\hline Transected & 18 & 0.5 & 0.67 & $0-3$ & $1 \cdot 0$ & 0.94 & $(1-3$ & 1 & 17 \\
\hline $20 \%$ Resected & 17 & $1 \cdot 0$ & $0 \cdot 88$ & $0-3$ & $2 \cdot 0$ & $1 \cdot 65$ & $0 \cdot 4$ & 4 & 13 \\
\hline $50 \%$ Resected All & 18 & $1 \cdot 0$ & 1.61 & $0-3+$ & $2 \cdot 0$ & $2 \cdot 44$ & $(1-5 \ddagger$ & 8 & $10^{*}$ \\
\hline $50 \%$ Resected Survivors & 17 & $1 \cdot 0$ & $1 \cdot 65$ & $0-3 \dagger$ & $2 \cdot 0$ & $2 \cdot 53$ & $0-5 \div$ & 8 & 9 \\
\hline $80 \%$ Resected All & 17 & $1 \cdot 0$ & 0.76 & $0-2$ & $3 \cdot 0$ & $3 \cdot 59$ & $0-11 \div$ & 5 & 12 \\
\hline $80 \%$ Resected Survivors & 7 & $1 \cdot 0$ & $1 \cdot(00$ & $0-2$ & $7 \cdot 0$ & $6 \cdot(0)$ & $2-11 \div$ & 4 & $3^{*}$ \\
\hline
\end{tabular}

${ }^{*} \mathrm{p}<0 \cdot(05, \quad \mathrm{p}<0 \cdot 01, \neq \mathrm{p}<0 \cdot 001$ vs transected group.

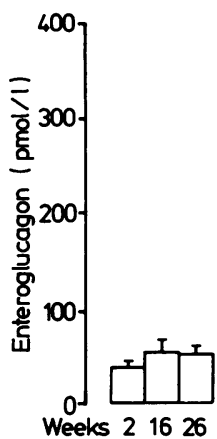

Resection Trans

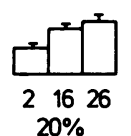

Fig. 3 Plasma enteroglucagon in the four groups at 2, 16 and 26 weeks. $\left({ }^{*} p<0.05,{ }^{* * *} p<0.001\right.$ vs transection group).

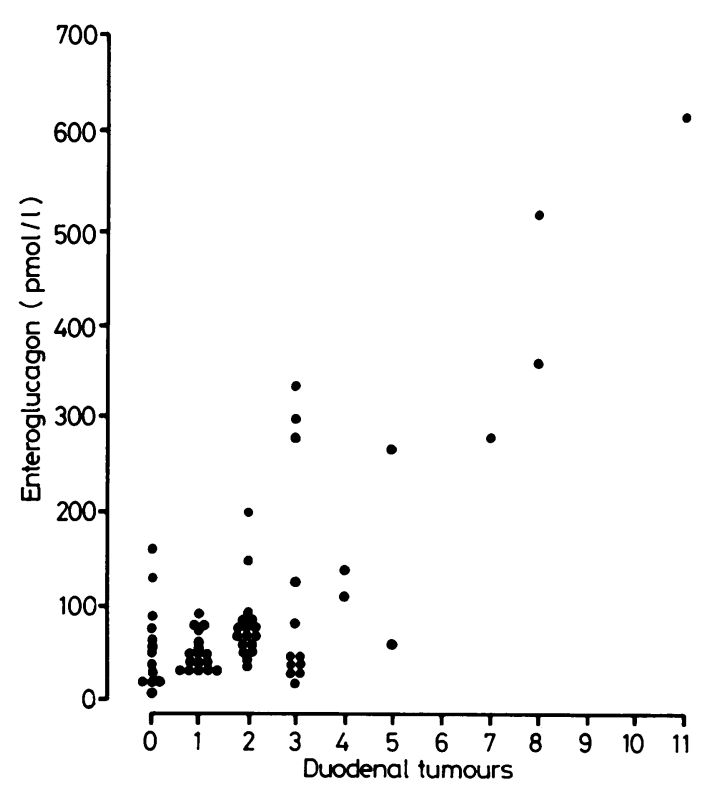

Fig. 4 Correlation between plasma enteroglucagon and duodenal tumours in each rat. $\left(r_{s}=0 \cdot 479, p<0.0(1)\right.$.

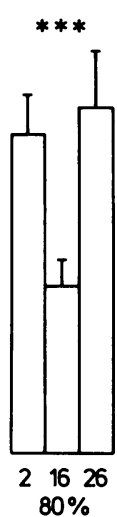

26 weeks. In the $50 \%$ resection group there was a small increase in enteroglucagon from $53.5 \pm 4.4 \mathrm{pmol} / \mathrm{l}$ in the transection group to $90.5 \pm 15.9 \mathrm{pmol} / \mathrm{l}$ at 26 weeks $(\mathrm{p}<0 \cdot 05)$. Twenty per cent resection produced no significant changes in enteroglucagon concentrations (Fig. 3). There was a strong positive correlation between enteroglucagon concentrations and the number of duodenal tumours $\left(r_{s}=0.479, p<0 \cdot 001\right)$ (Fig. 4) but no significant correlation was seen between colonic tumour number and enteroglucagon concentrations (Fig. 5).

\section{CRYPT CELL PRODUCTION RATE (CCPR)}

Small bowel resection resulted in a progressive rise in CCPR in the duodenum from $11.5 \pm 1.9$ cells/

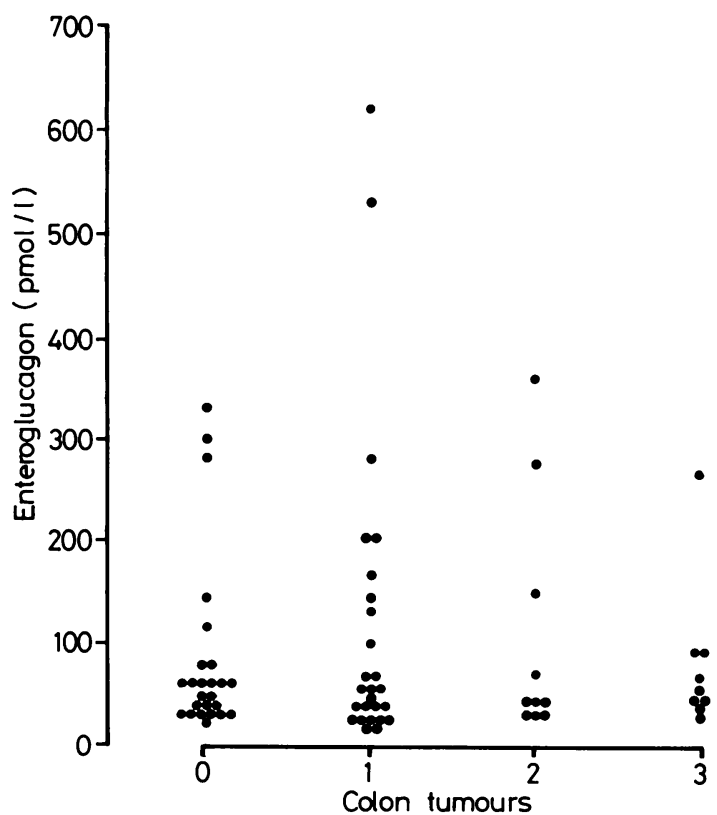

Fig. 5 Correlation between plasma enteroglucagon and colonic tumours. $\left(r_{s}=0 \cdot 228\right.$, not significant $)$. 


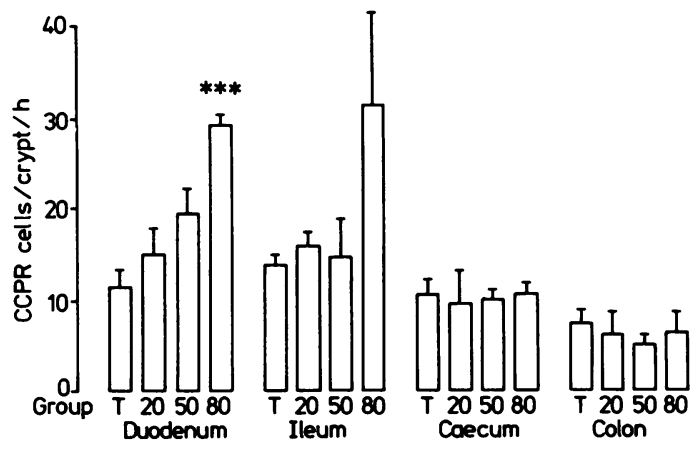

Fig. 6 Crypt cell production rate $(C C P R)$ in the four sites. $\left({ }^{* *} p<0.001\right.$ vs transection group).

crypt/h in the transection group to $29 \cdot 2 \pm 1 \cdot 4$ cells/ crypt $/ \mathrm{h}$ in the $80 \%$ resected group $(\mathrm{p}<0.001)$. In the ileum, only the $80 \%$ resected group showed a raised CCPR compared with transection from $13 \cdot 6 \pm 2 \cdot 6$ to $31.7 \pm 9.9$ cells/crypt/h but this was not statistically significant. No changes occurred in CCPR in either the caecum or descending colon after resection (Fig. $6)$. There was a positive correlation between the increase in duodenal CCPR and number of duodenal tumours $(r=0.99, p<0.01)$ but no correlation was found between caecal or colonic CCPR and colonic tumours.

\section{Discussion}

This study confirms previous reports that small bowel resection promotes intestinal neoplasia in carcinogen treated animals. ${ }^{1-4} 1920$ In the colon, maximal promotion of neoplasia was achieved with $50 \%$ small bowel resection. Eighty per cent resection resulted in fewer tumours than in the $50 \%$ group. This may be because there were only seven animals in this group surviving to 26 weeks and the incidence may have been higher if a larger proportion of animals had survived. Further, subtotal resection may result in a degree of malnutrition which may protect against the development of colonic tumours. ${ }^{19}$ Although rate of weight gain was the same between the four groups from four to 20 weeks, there was a fall in the average weight of the $80 \%$ resected group after this time.

In the duodenum, proximal small bowel resection resulted in a progressive promotion of neoplasia with increasing resection (Table 3 ). This change closely parallels CCPR in this site further confirming the association between hyperplasia and neoplasia previously reported. ${ }^{2021}$ Hormonal factors have been implicated in the trophic response of small bowel after resection. For example, luminal factors alone cannot explain the hyperplasia in isolated Thiry-Vella loops after resection. ${ }^{-1}$ In rats connected by vascular parabiosis, small bowel resection of one parabiont is reported as producing hyperplasia of the other. ${ }^{8}$ The suggestion that enteroglucagon may be important in the control of intestinal cell proliferation comes from several observations. In a patient with an enteroglucagon secreting renal tumour, gross villous hyperplasia was noted, but on resection of this tumour, intestinal morphology returned to normal. ${ }^{22}{ }^{23}$ In several studies in the rat, a close correlation has been found between plasma enteroglucagon and the proliferative status of the bowel in isolated Thiry-Vella loops of small bowel. ${ }^{1(-1)}$ Finally, partly purified enteroglucagon has been shown to increase the incorporation of ${ }^{3} \mathrm{H}$-thymidine into DNA of isolated cultured guinea pig ileum. ${ }^{24}$ While a positive correlation does not prove that there is a causal relationship, it does indicate that such a relationship may exist. We speculate that enteroglucagon may mediate, in part, the hyperplastic response in the duodenum and that, either directly or through this hyperplastic response, may promote duodenal neoplasia. The close association between duodenal tumour number and enteroglucagon does not negate this hypothesis (Fig. 4).

In the colon, small bowel resection has been shown to result in a mild hyperplastic response. ${ }^{5} 25-28$ This adaptive response, however, is limited and occurs with resections greater than $50 \%$ of proximal small bowel or distal resections. We can find only one report of a physiological systemic factor mediating colonic hyperplasia ${ }^{29}$ and enteroglucagon's role in the regulation of colonic mucosal growth is not known. In pharmacological doses, both gastrin ${ }^{30}$ and epidermal growth factor ${ }^{31}$ have been reported to exert a trophic effect on the colon but it is not known whether these agents act physiologically. In this study, a seven-fold rise in enteroglucagon in the $80 \%$ resected group did not result in increased crypt cell turnover either in the descending colon or the caecum, which suggests that enteroglucagon probably neither mediates colonic hyperplasia nor is associated with the promotion of colonic tumours by small bowel resection. We could show no changes in rate of cell proliferation in the colon with proximal small bowel resection and therefore no association between proliferative status of the colon and neoplasia. Measurement of CCPR is a less sensitive indicator of cell turnover in the colon than in the small bowel, however, and a small hyperplastic response might therefore not be observed. In addition, any small colonic hyperplastic response may have been masked in this study by the relatively large standard errors at this site, which may be because of individual differences in animals due to 
the presence of colonic and duodenal tumours. This study therefore does not refute previous reports associating hyperplasia of the colon with neoplasia in carcinogen treated rats. ${ }^{+20}$

Tumours of the external ear canal develop from Zymball's glands in response to azoxymethane administration. ${ }^{32}$ A promotion of ear canal tumours by small bowel resection was observed in the 50 and $80 \%$ intestinal resected groups in this study. The promotion of ear canal tumours by resection suggests a systemic factor as a mediator though other effects such as changes in host defence due to the resection may be responsible. While there is a similar pattern between enteroglucagon release and the promotion of ear canal tumours, further studies are required to clarify any possible role.

In conclusion, $80 \%$ small bowel resection resulted in a seven-fold rise in enteroglucagon concentrations and this rise closely correlates with both hyperplasia and promotion of tumours in the duodenum. This indicates that hormonal factors may play a role in the development or progression of intestinal tumours. In the colon, on the other hand, there is no evidence from this study that enteroglucagon either mediates hyperplasia or the promotion of tumours.

Mr A P Savage is in receipt of a Medical Research Council Research Training Fellowship. This work is supported by the British Medical Research Council. We would like to thank Dr K MacRae, Reader in Medical Statistics, for his help with statistical interpretation, and $\mathrm{Dr} \mathrm{H} \mathrm{B}$ Wayneforth and $\mathrm{Mr} \mathrm{R}$ Wilder of Charing Cross Hospital Animal Unit for their help in the care of the animals.

\section{References}

1 Williamson RCN, Bauer FLR, Oscarson JEA, Ross JS, Malt RA. Promotion of azoxymethane induced colonic neoplasia by resection of the proximal small bowel. Cancer Res 1978; 38: 3212-7.

2 Oscarson JEA, Veen HF, Ross JS, Malt RA. Ileal resection potentiates 1,2-dimethlhydrazine-induced colonic carcinogenesis. Ann Surg 1979; 189: 503-8.

3 Scudamore $\mathrm{CH}$, Freeman HJ. Effects of small bowel transection, resection, or bypass in 1,2dimethylhydrazine-induced rat intestinal neoplasia. Gastroenterology 1983; 84: 725-31.

4 Rainey JB, Davies PW, Williamson RCN. Relative effects of ileal resection and bypass on intestinal adaptation and carcinogenesis. Br J Surg 1984; 71: 197-202.

5 Nundy S, Malamud D, Obertop H, Sczerban J, Malt RA. Onset of cell proliferation in the shortened gut. Colonic hyperplasia after ileal resection. Gastroenterology 1977; 72: 263-6.
6 Sharp JG, Hanson WR, Osborne JW. The relationship between the compensatory response in the stomach and colon and the extent of small bowel resection in the rat. Virchows Arch [Cell Pathol] 1983; 44: 295-304.

7 Williamson RCN, Bauer FLR. Evidence for an enterotropic hormone: compensatory hyperplasia in defunctioned bowel. Br J Surg 1978; 65: 736-9.

8 Williamson RCN, Bucholtz TW, Malt RA. Humoral stimulation of cell proliferation in small bowel after transection and resection in rats. Gastroenterology 1978; 75: 249-54.

9 Tilson MD, Livstone EM. Radioautography of heterotopic autografts of ileal mucosa in rats after partial enterectomy. Surg Forum 1975; 26: 393-4.

10 Jacobs LR, Bloom SR, Dowling RH. Response of plasma and tissue levels of enteroglucagon immunoreactivity to intestinal resection, lactation and hyperphagia. Life Sci 1981; 29: 2003-7.

11 Sagor GR, Al-Mukhtar MYT, Ghatei MA, Wright NA. Bloom SR. The effect of altered luminal nutrition on cellular proliferation and plasma concentrations of enterogluagon and gastrin after small bowel resection in the rat. $B r J$ Surg 1982; 69: 14-8.

12 Sagor GR, Ghatei MA, Al-Mukhtar MYT, Wright NA, Bloom SR. Evidence for a humoral mechanism after small bowel resection. Exclusion of gastrin but not enteroglucagon. Gastroenterology 1983; 84: 902-6.

13 Gornacz GE, Al-Mukhtar MYT, Ghatei MA, Sagor GR, Wright NA, Bloom SR. Pattern of cell proliferation and enteroglucagon response following small bowel resection in the rat. Digestion 1984; 29: 65-72.

14 Cruse JP, Lewin MR, Clark CG. Corynebacterium parvum enhances colonic cancer in dimethylhydrazinetreated rats. $\mathrm{Br} J$ Cancer 1978; 37: 639-43.

15 Wright NA, Appleton DR. The metaphase arrest technique - A critical review. Cell Tissue Kinet 1980; 13: $643-63$.

16 Goodlad RA, Wright NA. Quantative studies on epithelial replacement in the gut. In: Titchen DA, ed. Techniques in the life sciences, $P 2$ digestive physiology. Ireland: Biomedical Press, 1982: P212/1-23.

17 Ghatei MA, Uttenthal LO, Christofides ND, Bryant MG, Bloom SR. Molecular forms of human enteroglucagon in tissue and plasma: Plasma responses to nutrient stimuli in health and in disorders of the upper gastrointestinal tract. J Clin Endocrinol Metab 1983; 57: 488-95.

18 Sunter JP, Appleton DR, Wright NA, Watson AJ. Pathological features of the colonic tumours induced in rats by the administration of 1,2-dimethylhydrazine. Virchows Arch [Cell Pathol] 1978; 29: 211-23.

19 Williamson RCN, Bauer FLR, Terpstra OT, Ross JS, Malt RA. Contrasting effects of subtotal enteric bypass, enterectomy and colectomy on azoxymethaneinduced intestinal carcinogenesis. Cancer Res 1980; 40: $538-43$.

20 Williamson RCN. Hyperplasia and neoplasia of the intestinal tract. Ann R Coll Surg Engl 1979; 61: 341-8.

21 Cooke T, Kirkham N, Stainthorp DH, Inman C, Goeting N, Taylor I. Detection of early neoplastic changes in experimentally induced colorectal cancer 
using scanning electron microscopy and cell kinetic studies. Gut 1984; 25: 748-55.

22 Gleeson MH, Bloom SR, Polak JM, Henry K, Dowling RH. Endocrine tumour in the kidney affecting small bowel structure, motility and absorptive function. Gut 1971; 12: 773-2.

23 Bloom SR. An enteroglucagon tumour. Gut 1972; 13: 520-3.

24 Uttenthal LO, Batt RM, Carter MW, Bloom SR. Simulation of DNA synthesis in cultured small intestine by partly purified enteroglucagon. Regulatory Peptides 1982; 3: 84.

25 Ryan GP, Dudrick SJ, Copeland EM, Johnson LR. Effect of various diets on colonic growth in rats. Gastroenterology 1979; 77: 658-63.

26 Urban E, Starr PE, Michel AM. Morphological and functional adaptations of large bowel after small bowel resection in the rat. Dig Dis Sci 1983; 28: 265-72.

27 Tilson MD, Michaud JT, Livstone EM. Early prolifera- tive activity in the left colon of the rat after partial small bowel resection. Surg Forum 1976; 27: 445-6.

28 Scarpello JHB, Cary BA, Sladen GE. Effects of ileal and caecal resection on the colon of the rat. Clin Sci Mol Med 1978; 54: 241-9.

29 Delvaux G, Case F, Willems G. Refeeding of fasting rats stimulates epithelial cell proliferation in the excluded colon. Gastroenterology 1984; 86: 802-7.

30 Johnson LR. The trophic action of gastrointestinal hormones. Gastroenterology 1976; 70: 278-88.

31 Goodlad RA, Wilson TJG, Lenton W, Gregory H, McCullagh KG, Wright NA. Effect of systemic and luminal administration of urogastrone on intestinal epithelial cell proliferation in parenterally fed rats. [Abstract] Gut 1984; 25: A1154.

32 Martin MS, Martin F, Michiels R, Bastien H, Justrabo E, Bordes M, Viry B. An experimental model for cancer of the colon and rectum. Digestion 1973: 8: 22-34. 